\title{
Analisis Kepuasan Pelayanan dan Loyalitas Pelanggan dengan Menggunakan Metode Servqual, IPA, dan QFD di Terminal Teluk Lamong
}

\author{
Dafazal Saffan, Bambang Syairudin, Fuad Achmadi \\ Program Magister Manajemen Teknologi \\ Institut Teknologi Sepuluh November Surabaya, Indonesia \\ e-mail: dafazalbachmid@yahoo.com, bambangsy@ie.its.ac.id, fuadachmadi@gmail.com
}

\begin{abstract}
Service is a very important element in the effort to increase customer satisfaction and loyalty. Basically, the position of these services is a supporting factor to the service activities of PT Terminal Teluk Lamong. The number of service users who did online booking in counters and complaints in the services provided to encourage researchers to conduct research. The study population was a customer Terminal Teluk Lamong the number 312 company. The total sample of 75 respondents using the sampling method used is purposive sampling and Slovin formula. The analysis used in knowing the fit between the expectations and reality, used models Cartesian diagram. The results of the Cartesius diagram is processed with the House of Quality in QFD. The results of the analysis of SERVQUAL and QFD shows that five (5) top priority in efforts to improve customer satisfaction Terminal Teluk Lamong, namely: (1) evaluate the SOP of the process behandle, (2) adding personel to the clerk TKBM in behandle locations, (3) provide specialized training for officers at the behandle location, (4) Trying to establish a communication network with the Customs, if the service users experiencing problems in the management of NPE, and (5) Increases forklift unit if necessary.
\end{abstract}

Keywords: job description, leadership, employees performance, working environment, motivation

\section{Pendahuluan}

Negara Indonesia merupakan negara kepulauan terbesar di dunia yang terdiri dari 17.058 pulau. Yang secara geografis terletak di antara Benua Asia dan Australia, serta diapit oleh Samudra Pasifik dan Samudra Hindia. Letak Negara Indonesia yang strategis menjadikan Indonesia mempunyai peranan penting dalam perdagangan di dunia.

Transportasi merupakan salah satu aspek paling penting dan strategis dalam memperlancar arus perdagangan tersebut. Dengan demikian, dibutuhkan pelabuhan sebagai tempat penghubung antara moda laut dengan moda darat. Pelabuhan sebagai penyedia jasa pelayanan jasa kepelabuhan diharapkan mampu memberikan pelayanan yang prima, sehingga pelanggan tidak dirugikan dengan peningkatan biaya akibat pelayanan yang tidak optimal.
PT Terminal Teluk Lamong merupakan perusahaan baru di bidang jasa Terminal Multipurpose dan Bongkar Muat peti kemas dan dibekali sarana dan prasarana dengan teknologi terkini di Indonesia. Salah satu jenis layanan yang diusahakan oleh PT Terminal Teluk Lamong yaitu kegiatan bongkar muat peti kemas.

Pelayanan merupakan unsur yang sangat penting di dalam usaha meningkatkan kepuasan pelanggan. Menurut Kottler (2005), kepuasan adalah tingkat perasaan seseorang setelah membandingkan kinerja (atau hasil) yang dirasakan dibandingkan dengan harapannya.

Di samping memiliki alat-alat yang canggih dalam kegiatan bongkar muat, Terminal Teluk Lamong memiliki fasilitas online booking melalui internet yang dapat diakses oleh seluruh pelanggan, sistem tersebut adalah hal yang baru diterapkan di dunia kepelabuhanan terutama di 
Indonesia. Tetapi masih banyak pelanggan yang tidak menggunakan fasilitas tersebut (manual) dan juga komplain mengenai pelayanan selama melakukan proses di Terminal.

Oleh karena itu, pengukuran kepuasan akan pelayanan yang diberikan oleh PT Terminal Teluk Lamong pada pengguna jasa dilakukan untuk mengetahui dan merencanakan strategi yang lebih baik di masa mendatang dan lebih meningkatkan kualitas pelayanannya agar dapat memenuhi keinginan dan kebutuhan pelanggan serta untuk meminimalisasikan masalah.

\section{Metode}

\section{A. Service Quality (Servqual)}

Pengukuran dengan metode servqual merupakan pendekatan used-based approach (pendekatan berbasis pengguna) dan kini sering digunakan di industri-industri jasa. Pendekatan ini didasarkan pada pemikiran bahwa kualitas tergantung pada orang yang memandangnya sehingga produk yang paling memuaskan preferensi

CONSUMER

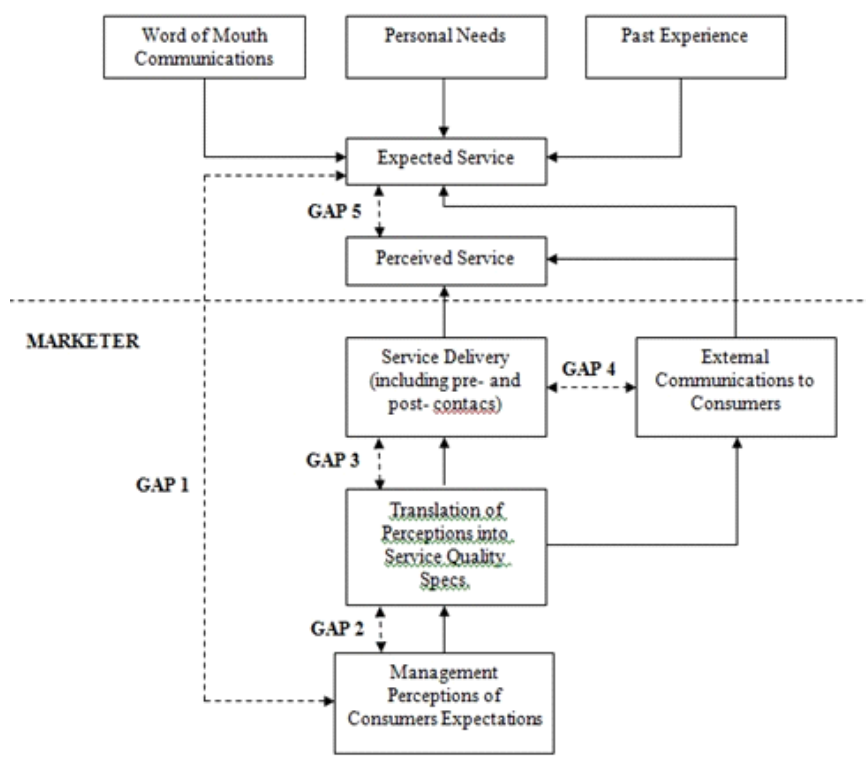

Gambar 1 Metode Konseptual Servqual seseorang merupakan produk yang berkualitas paling tinggi. Model yang dikembangkan oleh Zeithaml et al (1990) yaitu service quality dengan mengidentifikasi 5 kesenjangan yang menyebabkan kegagalan penyampaian jasa, dapat dilihat pada Gambar 1.

Metode Servqual membagi kualitas pelayanan kedalam lima dimensi, yaitu tangibles, reliability, responsive, assurance, dan emphaty.

\section{B. Importance and Performance Analysis (IPA)}

Metode Importance Performance Analysis (IPA) pertama kali diperkenalkan oleh Martilla dan James (1977) dengan tujuan untuk mengukur kepuasan pelanggan dalam produk atau servisnya. Interpretasi grafik IPA sangat mudah, di mana grafik IPA dibagi menjadi empat buah kuadran berdasarkan hasil pengukuran importance-performance sebagaimana terlihat pada Gambar 2.

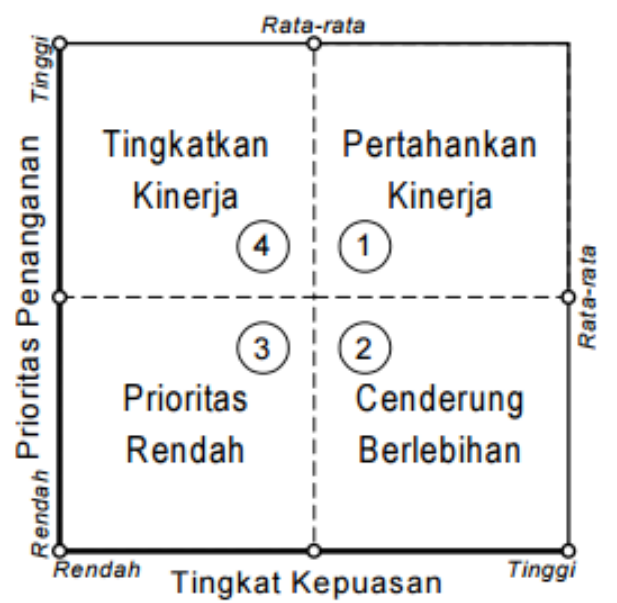

Gambar 2 Importance Performance Analysis (IPA) Matrix

\section{Quality Function Deployment (QFD)}

Menurut Subagyo 2004, Quality Function Deployment (QFD) adalah suatu cara untuk meningkatkan kualitas barang atau jasa dengan 
memahami kebutuhan konsumen, lalu menghubungkannya dengan ketentuan teknis untuk menghasilkan barang atau jasa di tiap tahap pembuatan barang atau jasa yang dihasilkan.

Dalam proses QFD digunakan alat House of Quality yang menyerupai sebuah rumah yang memuat kebutuhan pelanggan dan dibagi-bagi seperti pada Gambar 3.

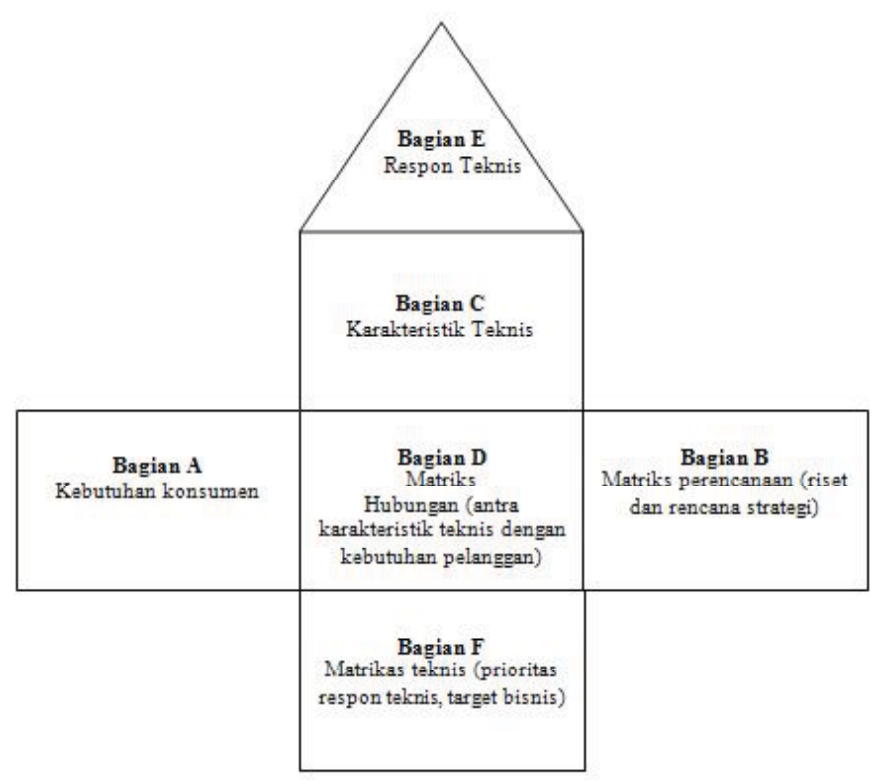

Gambar 3 House of Quality (HOQ)

\section{RESULT}

Penelitian ini menggunakan kuesioner terhadap 75 responden dengan pertanyaan survei mengenai harapan pengguna jasa dan kenyataan yang diterima oleh pengguna jasa terhadap kualitas layanan yang diberikan Terminal Teluk Lamong selama ini.

Data yang diolah terdiri dari data tingkat harapan dan data kepuasan yang dirasakan oleh pengguna jasa Terminal Teluk Lamong. Kedua data tersebut telah diolah dengan menggunakan Microsoft Excel dan program SPSS.

Uji reliabilitas pada penelitian ini menggunakan metode Cronbach Alpha untuk menentukan apakah setiap instrumen reliabel atau tidak.
Jika nilai Alpha>0,60 maka data tersebut reliable.

Tabel 1 Hasil Uji Validitas dan Reliabilitas Harapan

\begin{tabular}{|c|c|c|}
\hline Atribut & $\begin{array}{l}\text { Corrected Item- } \\
\text { Total Correlation }\end{array}$ & Cronbach Alpha \\
\hline R1 & 0,322 & \multirow{7}{*}{0,761} \\
\hline R2 & 0,404 & \\
\hline R3 & 0,486 & \\
\hline R4 & 0,515 & \\
\hline R5 & 0,619 & \\
\hline R6 & 0,646 & \\
\hline R7 & 0,430 & \\
\hline $\mathrm{A} 1$ & 0,465 & \multirow{2}{*}{0,631} \\
\hline A2 & 0,465 & \\
\hline $\mathrm{T} 1$ & 0,590 & \multirow{4}{*}{0,717} \\
\hline $\mathrm{T} 2$ & 0,522 & \\
\hline $\mathrm{T} 3$ & 0,456 & \\
\hline $\mathrm{T} 4$ & 0,524 & \\
\hline E1 & 0,315 & \multirow{6}{*}{0,621} \\
\hline E2 & 0,284 & \\
\hline E3 & 0,418 & \\
\hline E4 & 0,425 & \\
\hline E5 & 0,335 & \\
\hline E6 & 0,381 & \\
\hline S1 & 0,507 & \multirow{3}{*}{0,684} \\
\hline S2 & 0,454 & \\
\hline S3 & 0,547 & \\
\hline
\end{tabular}

\section{A. Service Quality (Servqual)}

Tabel 2 Hasil Survei Kuesioner

\begin{tabular}{|c|c|c|c|}
\hline \multicolumn{2}{|c|}{ Variabel } & Nilai Servqual & \% Kesesuaian \\
\hline \multirow{4}{*}{ X1 } & R1 & $-0,933$ & $80 \%$ \\
\cline { 2 - 4 } & R2 & 0,387 & $111 \%$ \\
\cline { 2 - 4 } & R3 & 0,027 & $101 \%$ \\
\cline { 2 - 4 } & R4 & $-0,933$ & $80 \%$ \\
\cline { 2 - 4 } & R5 & $-0,053$ & $99 \%$ \\
\cline { 2 - 4 } & R6 & $-0,547$ & $88 \%$ \\
\cline { 2 - 4 } & R7 & $-0,280$ & $94 \%$ \\
\hline \multirow{2}{*}{ X2 } & A1 & 0,133 & $103 \%$ \\
\cline { 2 - 4 } & A2 & $-0,373$ & $91 \%$ \\
\hline
\end{tabular}




\begin{tabular}{|c|c|c|c|}
\hline \multirow{4}{*}{ X3 } & T1 & $-0,600$ & $86 \%$ \\
\cline { 2 - 4 } & T2 & $-0,333$ & $92 \%$ \\
\cline { 2 - 4 } & T3 & $-1,080$ & $76 \%$ \\
\cline { 2 - 4 } & T4 & $-0,533$ & $87 \%$ \\
\hline \multirow{5}{*}{ X4 } & E1 & $-0,680$ & $85 \%$ \\
\cline { 2 - 4 } & E2 & $-0,173$ & $96 \%$ \\
\cline { 2 - 4 } & E3 & $-0,333$ & $92 \%$ \\
\cline { 2 - 4 } & E4 & $-0,427$ & $90 \%$ \\
\cline { 2 - 4 } & E5 & $-0,440$ & $90 \%$ \\
\cline { 2 - 4 } & E6 & $-0,373$ & $91 \%$ \\
\hline \multirow{4}{*}{ X5 } & S1 & $-0,147$ & $96 \%$ \\
\cline { 2 - 4 } & S2 & $-0,827$ & $81 \%$ \\
\cline { 2 - 4 } & S3 & $-0,360$ & $92 \%$ \\
\hline
\end{tabular}

Hasil perhitungan Gap 5 dimensi servqual menunjukkan bahwa hampir seluruh atribut bernilai negatif. Artinya pengguna jasa belum merasa puas dengan pelayanan Terminal Teluk Lamong.

\section{B. Importance and Performance Analysis (IPA)}

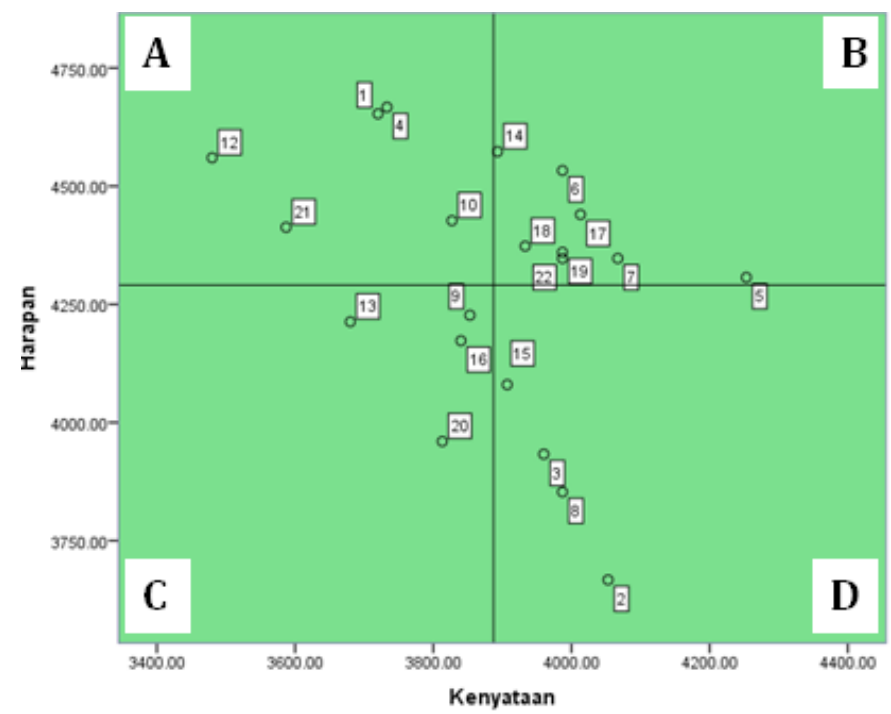

Gambar 4 Diagram Kartesius Variabel Mutu Pelayanan

Dalam kuadran A di atas ditunjukkan halhal yang perlu menjadi prioritas utama untuk segera ditangani oleh manajemen Terminal Teluk Lamong, karena hal-hal ini dinilai sangat penting oleh pengguna jasa dalam kenyataannya masih belum sesuai harapan. Item-item yang termasuk dalam kuadran ini adalah:

a. Kemudahan pengurusan NPE di Bea Cukai (X1).

b. Proses behandle berjalan dengan baik di hanggar/lokasi behandle (X2).

c. Peralatan untuk kegiatan receiving/delivery memadai di transfer area (X3).

d. Fasilitas shuttle bus cukup memadai (X4).

e. Petugas TKBM (Tenaga Kerja Bongkar Muat) di lokasi behandle (hanggar) telah membantu proses pemeriksaan bea cukai/karantina dengan baik (khusus jalur merah) (X5).

\section{Quality Function Deployment (QFD)}

Tabel 3 Matrix What

\begin{tabular}{|c|c|}
\hline No. & $\begin{array}{c}\text { How/Technical Response } \\
\text { What's Customer Needs }\end{array}$ \\
\hline 1 & X 1 \\
\hline 2 & X 2 \\
\hline 3 & X 3 \\
\hline 4 & X 4 \\
\hline 5 & X 5 \\
\hline
\end{tabular}

Tabel 4 Importance of What

\begin{tabular}{|c|c|c|}
\hline No. & $\begin{array}{c}\text { How/Technical Response } \\
\text { What's Customer Needs }\end{array}$ & $\begin{array}{c}\text { Importance of the } \\
\text { WHATs }\end{array}$ \\
\hline 1 & $\mathrm{X} \mathrm{1}$ & 4,65 \\
\hline 2 & $\mathrm{X} \mathrm{2}$ & 4,67 \\
\hline 3 & $\mathrm{X} \mathrm{3}$ & 4,43 \\
\hline 4 & $\mathrm{X} \mathrm{4}$ & 4,56 \\
\hline 5 & $\mathrm{X} \mathrm{5}$ & 4,41 \\
\hline
\end{tabular}

Tabel 5 Matrix How pada Quality Function Deployment (QFD)

\begin{tabular}{|c|l|}
\hline No. & \multicolumn{1}{|c|}{$\begin{array}{c}\text { What's Customer Needs } \\
\text { How/Technical Response }\end{array}$} \\
\hline 1 & $\begin{array}{l}\text { Menyediakan tempat khusus untuk cargo yang } \\
\text { belum memiliki NPE }\end{array}$ \\
\hline 2 & $\begin{array}{l}\text { Berusaha membentuk jaringan komunikasi dengan } \\
\text { pihak Bea Cukai, apabila pengguna jasa } \\
\text { mengalami kendala dalam pengurusan NPE }\end{array}$ \\
\hline 3 & $\begin{array}{l}\text { Melakukan evaluasi mengenai SOP kegiatan dari } \\
\text { proses behandle }\end{array}$ \\
\hline
\end{tabular}




\begin{tabular}{|c|l|}
\hline 4 & $\begin{array}{l}\text { Menambah unit forklift apabila memang dibu- } \\
\text { tuhkan }\end{array}$ \\
\hline 5 & $\begin{array}{l}\text { Memberikan alternatif baru selain harus me- } \\
\text { nunggu di Transfer Area, tetapi dapat langsung } \\
\text { masuk ke dalam CY }\end{array}$ \\
\hline 6 & $\begin{array}{l}\text { Menambah peralatan untuk menunjang kegiatan } \\
\text { delivery/receiving di Transfer Area }\end{array}$ \\
\hline 7 & Menambah armada bus \\
\hline 8 & Melakukan evaluasi mengenai jadwal shuttle bus \\
\hline 9 & $\begin{array}{l}\text { Memberikan training pelayanan khusus untuk } \\
\text { petugas TKBM di lokasi behandle }\end{array}$ \\
\hline 10 & $\begin{array}{l}\text { Menambah personel untuk petugas TKBM di } \\
\text { lokasi behandle }\end{array}$ \\
\hline
\end{tabular}

Karakteristik teknis yang memiliki korelasi positif dan kuat mengandung arti bahwa di antara karakteristik teknis yang satu dengan yang lainnya berkaitan erat dan saling menunjang dan begitu juga sebaliknya. Untuk mendapatkan pola hubungan ini dilakukan dengan cara brainstorming dengan pihak yang berkompeten dalam hal ini adalah Manager Operation dan Shift Manager.

Dari Matrix House of Quality dapat diketahui langkah-langkah mana yang perlu didahulukan oleh manajemen Terminal Teluk Lamong untuk dapat memenuhi permintaan pengguna jasa sebagai berikut.

1) Melakukan evaluasi mengenai SOP kegiatan dari proses behandle $(14,6)$.

2) Menambah personel untuk petugas TKBM di lokasi behandle $(13,9)$.

3) Memberikan training pelayanan khusus untuk petugas TKBM di lokasi behandle $(13,2)$.

4) Berusaha membentuk jaringan komunikasi dengan pihak Bea Cukai, apabila pengguna jasa mengalami kendala dalam pengurusan NPE $(11,2)$.

5) Menambah unit forklift apabila memang dibutuhkan $(9,6)$.

6) Melakukan evaluasi mengenai jadwal shuttle bus $(9,6)$.

7) Menyediakan tempat khusus untuk cargo yang belum memiliki NPE $(8,9)$.

8) Menambah armada bus $(8,1)$.
9) Menambah peralatan untuk menunjang kegiatan delivery/receiving di Transfer Area $(7,8)$.

10) Memberikan alternatif baru selain harus menunggu di Transfer Area, tetapi dapat langsung masuk ke dalam CY $(2,9)$.

\section{Kesimpulan}

\section{A. Kesimpulan}

Lima prioritas utama yang dapat dilakukan antara lain yaitu:

1) Melakukan evaluasi kegiatan mengenai $S O P$ dari proses behandle.

2) Menambah personel untuk petugas TKBM di lokasi behandle.

3) Memberikan training pelayanan khusus untuk petugas TKBM di lokasi behandle.

4) Berusaha membentuk jaringan komunikasi dengan pihak Bea Cukai, apabila pengguna jasa mengalami kendala dalam pengurusan NPE.

5) Menambah unit forklift apabila memang dibutuhkan.

Kesimpulan yang dapat diambil dari 5 (lima) prioritas utama yaitu bahwa Terminal Teluk Lamong harus lebih fokus terutama terkait dengan pelayanan di area behandle. Karena dari hasil yang sudah diolah banyak pengguna jasa yang masih belum terpuaskan terutama di area tersebut, baik itu mengenai kegiatannya, personel yang melakukan pekerjaan, dan juga alat bantu yang ada.

\section{B. Saran}

Dari hasil kesimpulan tersebut maka saran yang peneliti usulkan yaitu prioritas langkah-langkah perbaikan yang perlu didahulukan oleh 
manajemen Terminal Teluk Lamong untuk dapat memenuhi permintaan pengguna jasa yang nantinya akan dilakukan pemanfaatan secara optimal.

\section{Daftar Pustaka}

Alter, S. 2002. Information System: Foundation of E-Business. Prentice Hall.

Arikunto, S. 2006. Prosedur Penelitian Suatu Pendekatan Praktik. Jakarta: Rineka Cipta.

Aulia, T. 2011. Pengarub Kualitas Pelayanan Terhadap Kepuasan Pengguna Jasa Pada Pt. Pelabuhan Indonesia IV (Persero) Cabang Terminal Petikemas di Makassar. Universitas Hasanuddin Makassar.

Hermanto, A. 2008. Analisa Tingkat Kepuasan Konsumen Terhadap Pelayanan Terminal Peti Kemas Semarang. Universitas Diponegoro Semarang.

Huff, L.C. 2000. "An Integrated Model of Consumer Trust Formation." Proceeding of American Marketing Association Conference, Vol. 11, pp. 206-212.

Kotler, P. 1995. Manajemen Pemasaran Analysis Perencanaan dan Implementasi. Jakarta: Salemba Empat.

Kotler, P. 2001. Manajemen Pemasaran di Indonesia: Analisis, Perencanaan, Implementasi dan Pengendalian. Jakarta: Salemba Empat.

Kotler, P. 2007. Alih Bahasa: Benyamin Molan; Penyunting: Bambang Sarwiji. Manajemen Pemasaran, Edisi 12, Jilid 1. Jakarta: PT INDEKS.

Kotler, P. 2008. Alih Bahasa: Benyamin Molan; Penyunting: Bambang Sarwiji. Manajemen Pemasaran, Edisi 12, Jilid 2. Jakarta: PT INDEKS.

Kotler, P. and Gary A. 2012. Principle of Marketing, Fourteenth Edition. Pearson Education Limited, England.
Lesmana, A. 2008. Analisis Kepuasan Nasabah terhadap Pelayanan Bank Mandiri (Persero) Tbk di Bagian Retail \& Consumer Risk Group. Tesis. Universitas Gunadarma Depok. Lestari dan Siti M. 2009. Kepuasan Pelanggan dan Kualitas Pelayanan pada Pusat Pengembangan dan Pemberdayaan Pendidik dan Tenaga Kependidikan Bahasa Jakarta. Jurnal Psikologi, Vol. 2, No. 2.

Lupiyoadi, R dan Hamdani, A. 2011. Manajemen Pemasaran Jasa. Edisi Dua. Jakarta: Salemba Empat.

Lovelock, Christopher and Lauren W. 2002. Principles of Service Marketing and Management. Second Edition. Pearson Education International, Inc. Prentice Hall.

Nasution, M.N. 2005. Manajemen mutu terpadu (Total Quality Management), Edisi Kedua. Jakarta: Ghalia Indonesia

Rangkuti. 2003. Measuring Customer Satisfaction: Gaining Customer Relationship Strategy. Cetakan Kedua. Gramedia Pustaka Utama, Jakarta.

Stanton, W.J. 2001. Prinsip Pemasaran. Jakarta: Erlangga.

Shurety, S. 1999. E-business with Net.Commerce. Prentice Hall.

Sugiyono. 2012. Metodologi Penelitian Kuantitatif Kualitatif dan R\&D. Alfabetha: Bandung

Taylor, S.A. 2001. Assessing the Use of Regression Analysis in Examining Service Recovery in the Insurance Industry: Relating Service Quality, Customer Satisfaction, and Customer Trust. Journal of Insurance Issues, Vol. 24, pp. 30-57.

Widayat \& Amirullah. 2002. Riset Bisnis. Yogyakarta: Graha Ilmu.

Zeithaml V.A., A. Parasuraman, and Leonard L.B. 1990. Delivery Quality Service Balancing Costumer Perceptions and Expectation. New York: The Free Press. 